\title{
Investigating on Mobile Ad-Hoc Network to Transfer FTP Application
}

\author{
Ako Muhammad Abdullah \\ Computer Science Department \\ Faculty of Physical \& Basic Education \\ University of Sulaimani \\ Kurdistan Region-Iraq
}

\begin{abstract}
Mobile Ad-hoc Network (MANET) is the collection of mobile nodes without requiring of any infrastructure. Mobile nodes in MANET are operating as a router and MANET network topology can change quickly. Due to nodes in the network are mobile and thus can move randomly and organize arbitrarily regardless of the directions that generate great complexity in routing traffic from source to destination. To communicate with other nodes MANET nodes contain multiple applications and it needs the different level of data traffic. While data communicate different routing protocols require whereas every node must act as a router. Nowadays, different routing protocols have available for MANET. MANET protocols designed and implemented at the network layer have vital roles that affect the application running at the application layer. In this paper, the performance of On Demand Distance Vector (AODV), Dynamic Source Routing (DSR) and Geographic Routing Protocol (GRP) will be evaluated. The main purpose of this research is to analyze the performance of MANET routing protocols to identify "Which routing protocol has ability to provide the best performance to transfer FTP Application in high mobility case under low, medium and high density scenario?". The performance analyze with respect to Average End-to-End Delay, Media Access Delay, Network Load, Retransmission Attempt and Throughput. All simulations have been done using OPNET. On the basis of results show that the GRP gives better performance in End-to-End Delay, Media Access Delay, and Retransmission Attempt when varying network size and provide the best Throughput in small and medium network size. Simulation results verify that AODV gives better Throughput in a large network and lower Network Load in small and medium network size compared to GRP. DSR produces low Average Network load as compared to other protocols. The overall study of the FTP application shows that the performance of theses routing protocols differences by varying number of nodes and node speed. This paper results will produce enough information to identify the best routing protocol for MANET to transfer FTP application.
\end{abstract}

\section{Keywords-MANET; AODV; DSR; GRP; FTP Application}

\section{INTRODUCTION}

In recent years, a network structure is changing rapidly. In the area of the wireless network, Mobile Ad-hoc Network (MANET) is the most demanding field. MANET is a dynamic distributed system and which has no fixed infrastructure and it has mobile devices or users that generally known as nodes each one of which equip with radio transmitter and receiver. In this network each mobile nodes can establish a communication with each other directly within transmission range. Otherwise the nodes between them forward the packets for them from source to destination. Every node acts as a router to forward the packets to other nodes whenever required [1].

Routing protocols has an important role to find route packets from source to destination among randomly distributed nodes. There are many protocols have proposed for MANET.

The routes change very fast and frequent with the dynamic nature of network topology, and so the routing protocols play significant roles in handling it [2]. They need be capable to ensure the delivery of packets safely to their destinations. MANETs has ability to handle topology changes malfunctions in nodes through network reconfigurations due to wireless mobile ad-hoc network for several types of applications are very flexible and suitable as allowing the establishment of temporary communication without any preinstalled infrastructure. To find a route between the end-points is a main problem in multi-hop ad-hoc dynamic. The problem is further aggravated because of the nodes mobility. [5].

Nowadays, to handle this problem many different approaches are proposed. However, it is very difficult to decide which one is best routing protocol. Other aspects of MANET are also dynamic changing network topology of nodes.

The purpose of this paper is to evaluate the performance of proactive and reactive routing protocols in MANET. Nowadays, different routing protocols have available to transfer data over MANET. However, these protocols have different behaviors with respect to wireless routing perspective. The main problem is to choose the correct routing protocol is reliable and efficient for MANET.

The main questions arise for the evaluation of these problems such as which routing protocols has the ability to provide a better performance in MANET? And what factors can be affected the performance of these routing protocols. To answer all these questions, we will deploy the different scenarios with varying network size and speed under different metrics.

In this study, the performance evaluation of these routing protocols such as AODV, DSR, and GRP will be carried out to determine which routing protocols has the ability to provide 
the best performance to transfer FTP application over MANET. Our evaluation metrics is End-to-End Delay, Media Access Delay, Network Load, Retransmission Attempts and Throughput. Different scenarios will be simulated based on the above mentioned metrics and from the results we can decide which routing protocols has ability to provide the best suitable for transferring FTP application over MANET.

This paper is organized as follows: related works discuss in Section 2. In Section 3 we describe routing protocols design issues in MANET. Next section presents a brief overview of MANET routing protocols that we evaluate. The Simulation environment discuss in Section 5. Section 6 describes matrices used in this paper. Results and analysis presents in Section 7. Finally, we provide a conclusion and future work in Section 8.

\section{RELATED WORK}

In [8], Shah et al. compared the performance of AODV, DSR and DSDV routing protocols under different routing metrics such as network size, network load and mobility. They used NS-2. According to the results that they have obtained that both DSR and AODV perform better than DSDV under mobility. In [6], Kaushik et al. do a performance comparison of AODV, DSDV and DSR. The concluded that AODV performs predictably with low mobility virtually to deliver data at nodes and it has problem when node mobility increases. However, in this situation DSR has ability to provide the good performance when that node has mobility and DSDV performs almost as well as DSR but it requires many routing overhead packets. Furthermore, dropped packets and packet delay ratio are concerned and with the large of nodes the AODV and DSR better than DSDV. In addition, DSDV performance is better for less mobility and less number of nodes.

In [3], Abdullah et al. evaluate the performance of AODV and DSR protocols to transfer multimedia data over MANET. Performance of these routing protocols is evaluated under different metrics such as network load, throughput and end-toend delay. During the simulation they have changed network size. They concluded that AODV perform better than DSR under high mobility and varying network size.

In [4] Al-Maashr et al. evaluate the performance of AODV, DSR and OLSR in the presence of the burst selfsimilar traffic under four different metrics such as routing overhead, delivery ratio, end-to-end delay and throughput. They concluded that DSR protocol performs well with burst traffic models compared to AODV and OLSR in terms of delivery ratio, end-to-end delay and throughput. On the other hand, OLSR performed poorly in the presence of self-similar traffic at high mobility especially in terms of data packet delivery ratio, routing overhead and end-to-end delay. As for AODV routing protocol, the results show an average performance yet remarkably low and stable end-to-end delay.

Gupta et al. [7] the performance of AODV, DSR and TORA analyzed. The simulator used was Network Simulator Version 2 (NS-2). The simulation was carried out in a field of $500 \mathrm{~m} \times 500 \mathrm{~m}$ and the number of nodes in the network was 50 nodes. CBR traffic was used as the traffic source and the simulation time was 200 seconds. The performance metrics used were average end-to-end delay and Packet Delivery Fraction. The results showed that the AODV protocol has the best overall performance and the DSR protocol is suitable for networks with moderate mobility rate and since it has a low overhead that makes it suitable for low power network and low bandwidth. The results also demonstrated that TORA protocol is suitable for operation in large mobile networks having a dense population of nodes.

Naumov and Gross [8] analyzed the impact of the network size up to 550 nodes, nodes density, nodes mobility and suggested data traffic on DSR and AODV performance.

The authors performed the experimented in the areas of $2121 \mathrm{~m} \times 425 \mathrm{~m}, 3000 \mathrm{~m} \times 600 \mathrm{~m}, 3675 \mathrm{~m} \times 735 \mathrm{~m}, 4250 \mathrm{~m} \times$ $850 \mathrm{~m}$ and $5000 \mathrm{~m} \times 1000 \mathrm{~m}$. The traffic used was CBR. The performance metrics used were average end-to-end delay, Packet Delivery Fraction and routing overhead. The results illustrated that the AODV and DSR protocols demonstrated good scalability with respected to the number of nodes and density of nodes in stationary scenarios with a low number of traffic source. However, as the mobility rate increases, the routing overhead of DSR prevent this protocol from delivering data packets effectively.

\section{Routing PROTOCOL Design IsSUES}

When designing MANET routing protocols a number of issues are considered. Designing routing protocol is very challenging because the distributed state of unreliable environment they are found in such as limited network capacity, dynamic topology and different kind of wireless communication constraints. Several of these constrains are interference and hidden collisions, variable link quality and energy constrained nodes. In addition, hidden and exposed terminal and limited resource in terms of power are a vital problem that will be considered when routing protocol is designed [10].

\section{A. Distributed State in Unreliable Environment}

To performance routing protocols the status and condition of the environmental challenges is an important role. In addition, in any unreliable environment for the distribution of resource becomes a challenge to enable communication, due to routing protocols have to consider best utilization of resources such as processing power, battery life and bandwidth [11].

\section{B. Dynamic Topology}

Due to the network topology in mobile ad-hoc network is dynamically changing, therefore causing sessions of transferring packet to suffer from interferences leading to frequent path breaks. From the network range when a destination or intermediate node in a route dis appears the interference occurs. Moreover, when a route broken it is important for routing protocol to find a new route and build a new topology efficiently. The network load causing overhead if lowered, the overall performance will be increased and in any MANET routing protocol the mobility management is extremely important due to it justifies the need for efficiency [20]. 


\section{Limited Bandwidth}

MANET is limited in radio bandwidth compared to wire network with an abundant bandwidth therefore, data transfer rates are less than those of wired networks. This increased the need for a routing protocol to optimally use the bandwidth. Furthermore, limited bandwidth results in less stored topology information. For an efficient routing protocol complete topology information is required. However, in MANET routing protocol cannot be case as this will cause an increase in node control messages and overheads which loses more bandwidth. The purpose of control message is a message that nodes are used to establish connections before packet messages are transfer over the network. In addition, a balanced usage of the limited bandwidth is required an efficient routing protocol [17].

\section{Resource Constraints}

In MANET two resource constraints are essential to nodes which are battery life and processing power. Increasing power consumes more battery life is limited for nodes in a MANET. When overheads occur more processing and battery life is utilized to resolve the situation due to it is important to design a routing protocol that efficiently to reduce the limited life of battery life and using less processing power [18].

\section{E. Interference and Collisions}

Collisions occur during simultaneously transmission of two nodes when each node does not know about each other transmission. The exposed terminal problem contributes to the inability of a node that has been blocked due to transmission of a nearby node to another node, thus the radio reusability spectrum is affected, when spectrum is affected transmission cannot occur so it is important to correct the transmission and promote handshakes [19].

\section{MAnet Routing PROTOCOLS}

Routing is a process of finding paths from a known source to the destination nodes [15]. In recent years, different routing protocols have designed and developed for Mobile Ad-hoc Network to establish communication and transfer data between nodes. These protocols can be classified into three groups such as Flat, Hierarchical and Geographical routing [16]. This paper focuses on three routing protocols that are Ad-hoc On Demand Distance Vector (AODV), Dynamic Source Routing (DSR) and Geographic Routing Protocol (GRP).

\section{A. Ad-hoc On-Demand Distance Vector Routing (AODV)}

AODV routing protocol is a reactive routing protocol in MANET. The operation of AODV is done by using two mechanisms. First one is a Route Discovery and second one is a Route Maintenance. Route Discovery process starts to find the routes from source to destination when the source node does not have routing information in its table to send data to the destination. Route Discovery begins with broadcasting a Route Request (RREQ) packet by the source node to its neighbors [12]. RREQ packet contains broadcast ID, two sequence numbers, hop count and the address of source and destination [13]. The receiving RREQ packet by intermediary nodes can do two steps: intermediary nodes will be rebroadcast the RREQ packet to its neighbors if it is not the destination node. Otherwise, it will be the destination node and then it will send a unicast replay message, Route Replay (RREP), directly to the source from which it was received the RREQ packet. A copied RREQ will be ignored due to in MANET each node has a sequence number. When a mobile node needs to start route discovery process, it includes its sequence number and the most fresh sequence number it has for destination. Furthermore, when the intermediate node receives the route request packet directly reply to the route request packet only when the sequence number of its path is equal to or larger than the sequence number contained in the route request packet from the intermediate node a reverse path to the source forms with storing the address for nodes which initial copy of Route Request [14].

In addition, some routes are expired and should be dropped from the table due to that routes are not applied within their life time period but the life time period is updated for route and are not expired when routes are used by nodes. If a source node wants to send data to some destination, at the first time it must be reached to the routing table and when it can find the route, it will use it. Otherwise, source node must be started a route discovery to find a route [15]. Moreover, AODV uses Route Error (RERR) message to notify the other nodes regarding some failures in other nodes or links [9].

\section{B. Dynamic Source Routing (DSR)}

DSR is another reactive routing protocol that discovers and maintains routes between nodes. DSR also uses the concept of source routing. In source routing the sender knows all hopby- hop routes to the destination [21]. In addition, it uses the route cache to store all the routes. When mobile node is attempted to send a data packet to the destination it does not know the route. Each node has ability to maintain a route cache with route entries which are updated continuously and DSR protocol is not required periodic routing packets. It is used to updates its route caches by finding new routes [22]. Furthermore, DSR can handle unidirectional links. The sender of the packets controls and selects the route used for its own packets, which has also the capability to support features such as load balancing [8].

\section{Geographic Routing Protocol (GRP)}

In wireless mobile ad-hoc network Geographic Routing Protocol (GRP) has become one of the most suitable routing strategy due to its scalability and there is no need to maintain explicit routes [24]. The principle approach in geographic routing is depended on geographic position information instead of using the network address.

In other word, the source sends a message to the geographic location of the destination instead of using the network address. Each node has ability to determine its own location and that the source node takes responsibility to aware of the location of the destination. In addition, information that contains in a message can be routed to the destination without knowledge of a prior route discovery such as GEoCast, GPSR, DREAM and LAR or network topology [31]. Node can find the best route that relying on the gather position information and transmit the data continuously even if the current route is 
disconnected [25]. This method helps to reduce a slow transmission with highest control messages as an overhead.

To optimize the flooding GRP can divide the network into quadrants and it updates its flooding position when a network node moves and crosses a quadrant. Also, by exchanging the HELLO messages from other network nodes can identify their positions [26].

\section{- GRP Techniques}

GRP uses various approaches such as Single-Path, MultiPath and Flooding-Based Strategies for transferring data from source to destination [27]. Two techniques are used by Single-Path strategies that are Greedy Forwarding and Face Routing. In each steps the Greedy Forwarding using only local information to bring the message closer to the destination. Thus, each node has ability to forward the message to the neighbor that is most suitable from a local point of view [28].

In each step (Greedy Forwarding), the most suitable neighbor can be the one who minimizes the distance to the destination. Alternatively, one can consider another notion of process, namely the projected distance on the sourcedestination-line (MFR-NFP) or the minimum angle between neighbor and destination (Compass Routing) [29]. Not all of these strategies are loop free, i.e. a message can circulate among nodes in a certain constellation. It is known that the basic greedy strategy and MFP are loop free, whereas NFP and Compass Routing are not [30].

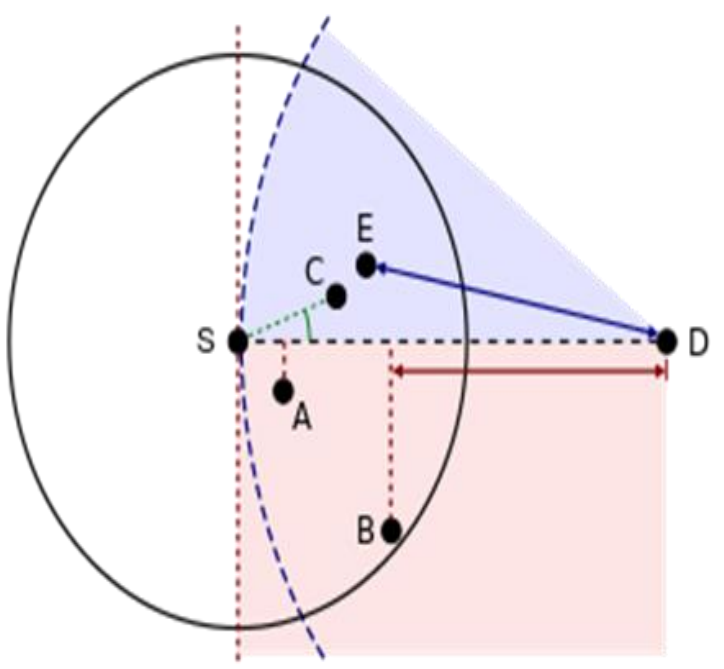

Fig. 1. Greedy Forwarding Techniques

Greed Forwarding variants: The source node $(\mathrm{S})$ is using various techniques to discovery a relay node for sending a message to the destination node (D).

$A=$ NFP (Nearest with Forwarding Progress).

$\mathrm{B}=$ MFR (Most Forwarding Progress with Radius).

$\mathrm{C}=$ Compass Routing.

$\mathrm{E}=$ Greedy
Furthermore, where there is no neighbor closer to the destination, Greedy Forwarding can lead into a dead end. Then Face Routing has ability to find a path to another node and helps to recover from that situation, where Greedy Forwarding can be resumed. In this network to ensure that the message is received by the destination a recovery strategy such as Face Routing is necessary.

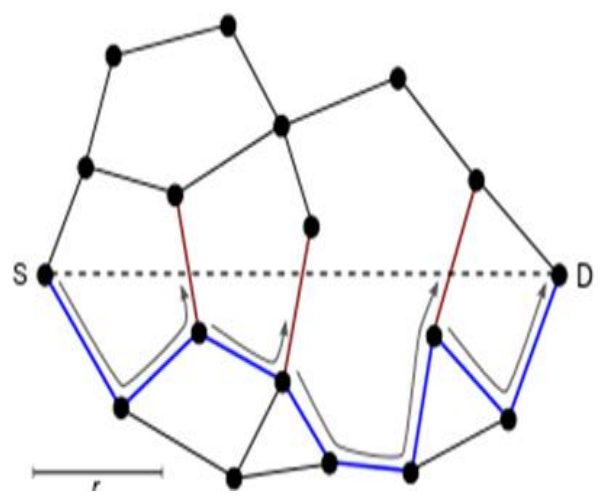

Fig. 2. Face Routing Techniques

\section{SIMULATION ENVIRONMENT}

To evaluate and investigate the performance of the routing protocols for transferring FTP traffic over MANET network, we employed OPNET Modeler 14.5 (Optimized Network Engineering Version 14.5) in our simulation. Fig. 3 demonstrates the simulation setup of one scenario consists of 80 mobile nodes, Wireless LAN Server, Application, Profile and Mobility Configuration. In this paper the simulation models were run with three scenarios. In each scenario network size was changed. In first scenario we have 20 mobile nodes. In second scenario the numbers of mobile nodes are increased into 40 nodes and the last scenario the mobile nodes were consisted of 80 nodes. In each scenario mobile nodes were moving at speed of 20 meters per second with a pause time of 600 seconds. The main purpose was to model the behavior of the routing protocols under varying network size and speeds.

In this research, each scenario was run for 1800 second and a campus network was model within an area of $1200 \mathrm{~m} \mathrm{x}$ $1200 \mathrm{~m}$ and the mobility model used "Random Waypoint Model". Random Waypoint is a mobility model that used by node to choose a destination randomly and moves towards it in a straight line with a constant velocity [32]. We take the FTP traffic to analyze the effects on routing protocols. The FTP was selected as traffic medium load on routing protocols. In this simulation the protocols that were studied are AODV, DSR and GRP. The nodes in the MANET supported a data rate transmission of $11 \mathrm{Mbps}$ with a power of 0.005 watts. The packet size for modelling was 20 frames. In Table 1 present the simulation parameters that are used in this study. To evaluate the performance of AODV, DSR and GRP protocol to transfer FTP application over MANET network we were considered five parameters such as End-to-End Delay, Media Access Delay, Network Load, Retransmission Attempt and Throughput. 


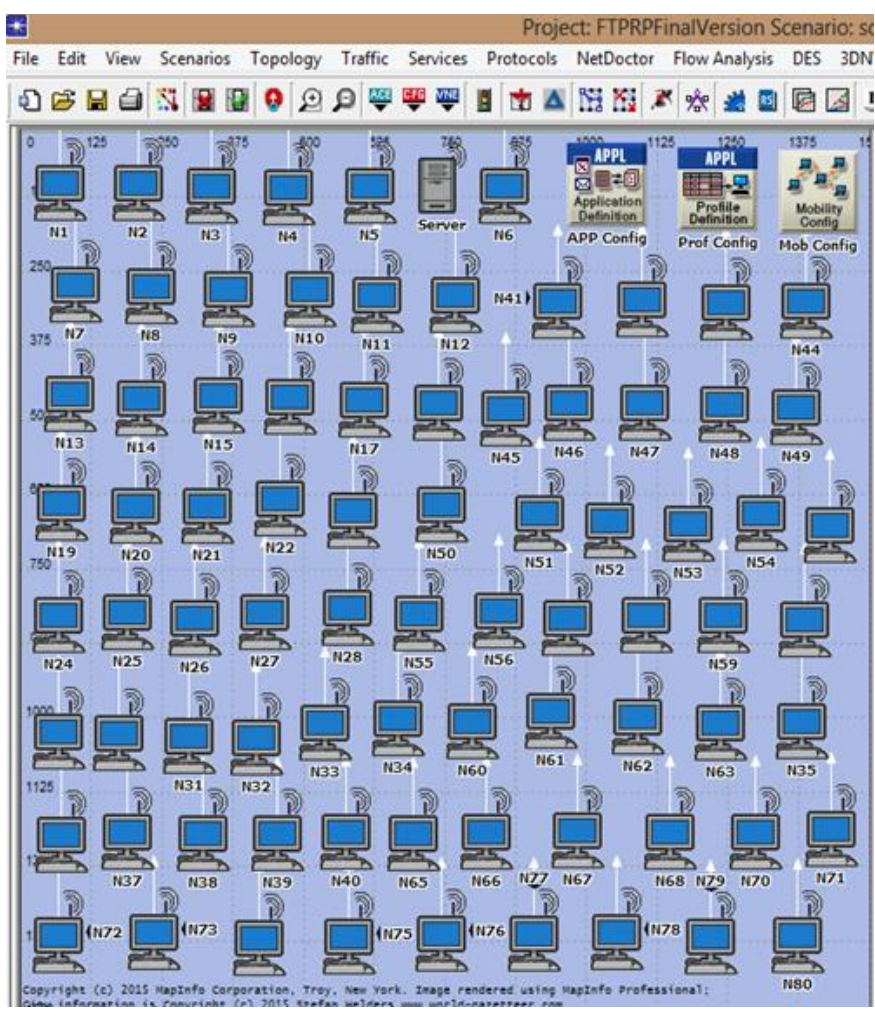

Fig. 3. Simulation Setup

TABLE I. PARAMETERS OF SIMULATION

\begin{tabular}{|l|l|}
\hline Simulation Time & 1800 second \\
\hline Simulation Area & $1200 \mathrm{~m}$ x 1200m \\
\hline Number of Nodes & $20,40,80$ \\
\hline Application Traffic & FTP Traffic (Medium Load) \\
\hline File Size & 20 Frames \\
\hline Data Rate & $11 \mathrm{Mbps}$ \\
\hline Mobility Algorithm & Random Way Point \\
\hline Routing Protocol & AODV, DSR, GRP \\
\hline Performance Metrics & $\begin{array}{l}\text { End-to-End Delay, Media Access } \\
\text { Delay, Network Load, } \\
\text { Retransmission Attempt, Throughput. }\end{array}$ \\
\hline
\end{tabular}

\section{PERFORMANCE Metrics}

To evaluate the best routing protocols for transferring FTP application over MANT network we use five different metrics such as End-to- End Delay, Media Access Delay, Network Load, Retransmission Packet Attempt and Throughput.

\section{A. End-to- End Delay}

It is defined as the average time between the sources generates and the data packet to the destination receives it across a MANET. It is expressed in second. Hence in the network all the delays are called packet End-to-End Delay. In the network the delay consists of Propagation Delay (PropD), Processing Delay (PD), Transmission Delay (TD), Queuing Delay (QD) [33].

Average End - to - End Delay $=\frac{\sum_{i=0}^{n} \text { Time Packet Received } i-\text { Time Packet Sent } i}{\text { Total Number of Packets Received }}$

\section{B. Media Access Delay}

It is providing the results for a received packet with a routing Address Resolution Protocol (ARP) and control packet reply transmitted by MAC layer. For each frame, this delay is calculated as the duration from the time when it is inserted into the transmission queue, which is arrival time for higher layer data packets and creation time for all other frames types, until the time when the frame is sent to the physical layer for the first time. Media Access Delay is very useful metrics to identify congestion hot spots and measure link interference in MANET [36]. In addition, it can be used to improve network throughput in multi-rate networks [37].

\section{Retransmission Packet Attempt}

Retransmission Attempt can be defined as the total number of retransmission attempt by WLAN MAC in the network until either packet is successfully transmitted or it is discarded as a results of reaching short or long retry limit [38].

\section{Network Load}

Network Load is defined as the total amount of data traffic being carried by the network. When there is excess traffic in the network which is unable to be controlled is known as Network Load. The efficient network can easily cope with large traffic coming in and to make a best network. High Network Load affects the MANET routing packets that reduce the delivery of packets for reaching to the channel [34].

\section{E. Throughput}

Throughput represents as the ratio of the amount of data reaches from the source to the destination. The time it takes by the destination to receive the last packet is called Throughput. It is expressed as bytes or bits per second [35]. It can be expressed as:

$$
\text { Throughput }=\frac{\text { Number of Delivered Packet } * \text { Packet Size } * 8}{\text { Total Duration of Simulation }}
$$

\section{RESULTS AND ANALYSIS}

In this section, the experiments results are presented and discussed. Our protocols evaluations are done according to the performance metrics, varying network size and speed mobile nodes. In each scenario, we were considered with a constant speed of 20 meters/second and pause time is considered in this network environment in analyzing the protocols performance and is set to 600 second and then each protocol performance is observed on FTP traffic medium load.

\section{A. Average End-to- End Delay}

In Fig. 4 the simulation results for the 20 mobile nodes on AODV, DSR and GRP protocols over FTP traffic shows that the End-to-End Delay for GRP routing protocol is lower than that of AODV and DSR. However, we can see a very small difference between AODV and GRP when GRP End-to-End Delay is equal to $0.0003903 \mathrm{sec}$ and $\mathrm{AODV}$ is equal to $0.0003948 \mathrm{sec}$. in this scenario DSR protocol quite high delay compared to AODV and GRP. It is because the DSR protocol is using the cache route causing the higher delay that it is equal to $0.0020406 \mathrm{sec}$ and DSR protocol needs to find the paths for transmitting the data and when it receives the data 
for transmission it will results in such incremented delay and then it is observed to decrease gradually.

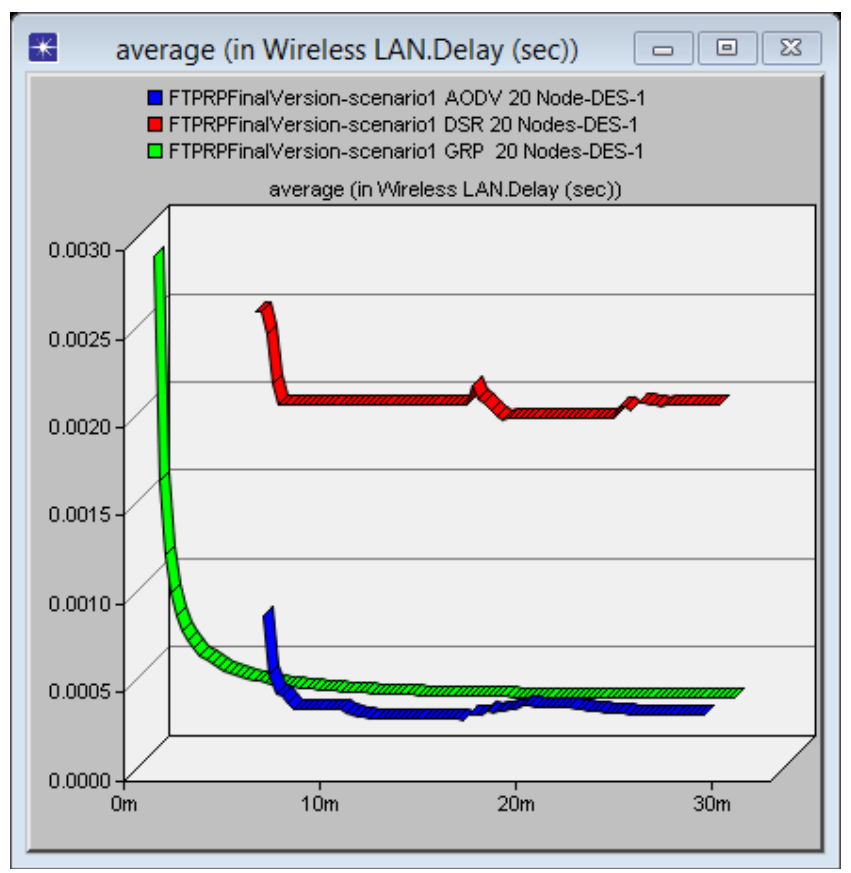

Fig. 4. End-to-End Delay for 20 Nodes

Second scenario is developed by using 40 mobile nodes with AODV, DSR and GRP routing protocol over FTP traffic. In Fig. 5 the simulation results for the 40 mobile nodes demonstrate that the delay in DSR is the highest and sharply increased is equal to $0.00434 \mathrm{sec}$. In this scenario the AODV is higher than GRP and the GRP have a minimum delay is equal to $0.000534 \mathrm{sec}$ whereas AODV is equal to 0.000932 sec.

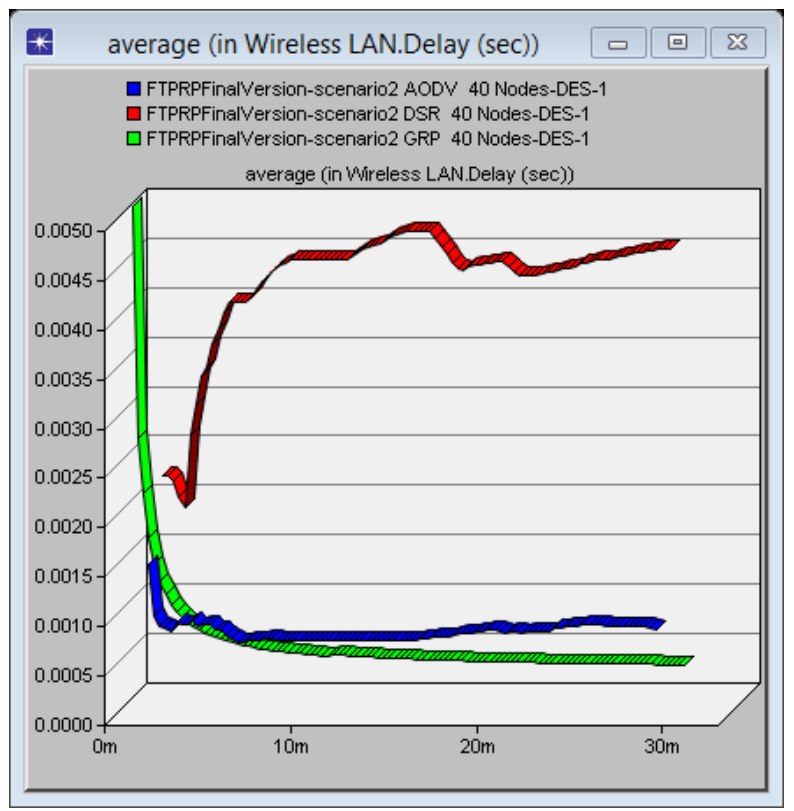

Fig. 5. End-to-End Delay for 40 Nodes
In third scenario when the number of mobile nodes is equal to 80 nodes. We can observe the average End-to-End Delay for the DSR protocol for FTP medium load traffic. According to the result, we can see DSR protocol shows higher delay that is equal to 0.00648 sec. Fig. 6 shows the delay for each protocol. It shows that the GRP protocol performs better than the other two protocols. For 80 mobile nodes network, delay of GRP is about $0.000719 \mathrm{sec}$ and in AODV is about $0.00185 \mathrm{sec}$. According to the results we have obtained from three scenarios, AODV protocol has the lower delay than DSR, with the increase the number of mobile nodes in the network. Due to DSR routing protocol uses cached routes and more offer sending of traffic onto stale routes causes retransmissions and leads to excessive delays. In addition, the GRP routing protocol has ability to provide the minimum delay as compared to AODV and DSR routing protocol because GRP setup quick connection between network nodes without creating major delays for both real and non-real time traffic. This is because that GRP protocol does not need much time in a route discovery mechanism. The routes are always available in a routing table. Moreover, in GRP the information is gathered rapidly at a source node without spending a large amount of overheads.

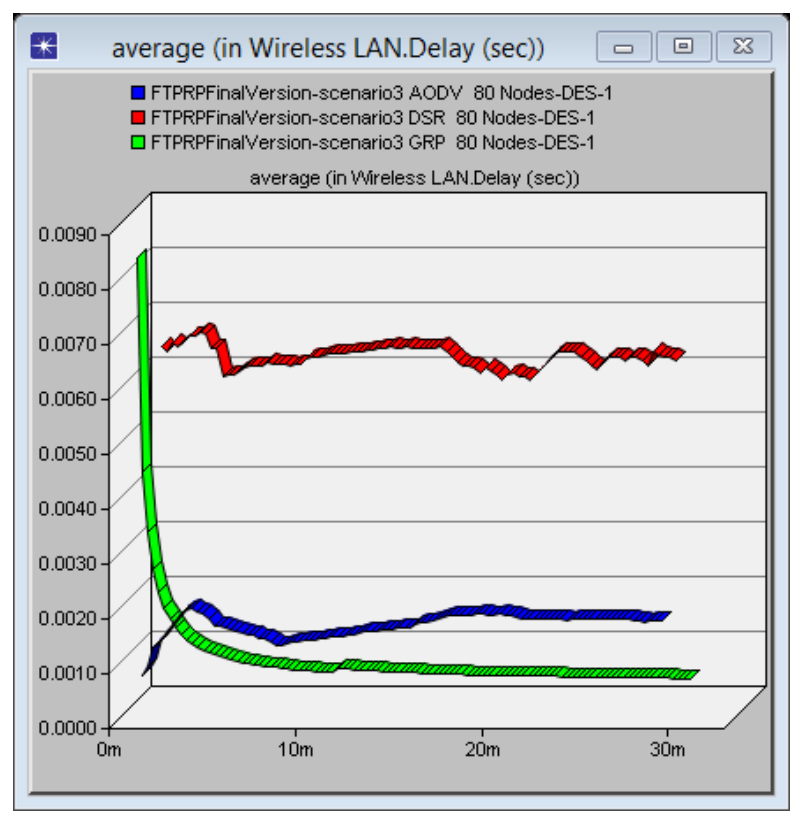

Fig. 6. End-to-End Delay for 80 Nodes

\section{B. Media Access Delay}

Three scenarios are generated to evaluate the Media Access Delay attempt of AODV, DSR and GRP protocols. In first scenario when the number of mobile node is 20 . As it illustrates from the Fig. 7 that Media Access Delay of GRP protocol are less than AODV and DSR while the nodes are mobile. The average peak value of GRP is $0.000188 \mathrm{sec}$. So AODV performs better than and less Media Access Delay compared to DSR that is $0.000362 \mathrm{sec}$ whereas Media Access delay for DSR is $0.00221 \mathrm{sec}$. In the medium load traffic network DSR had high delay. 


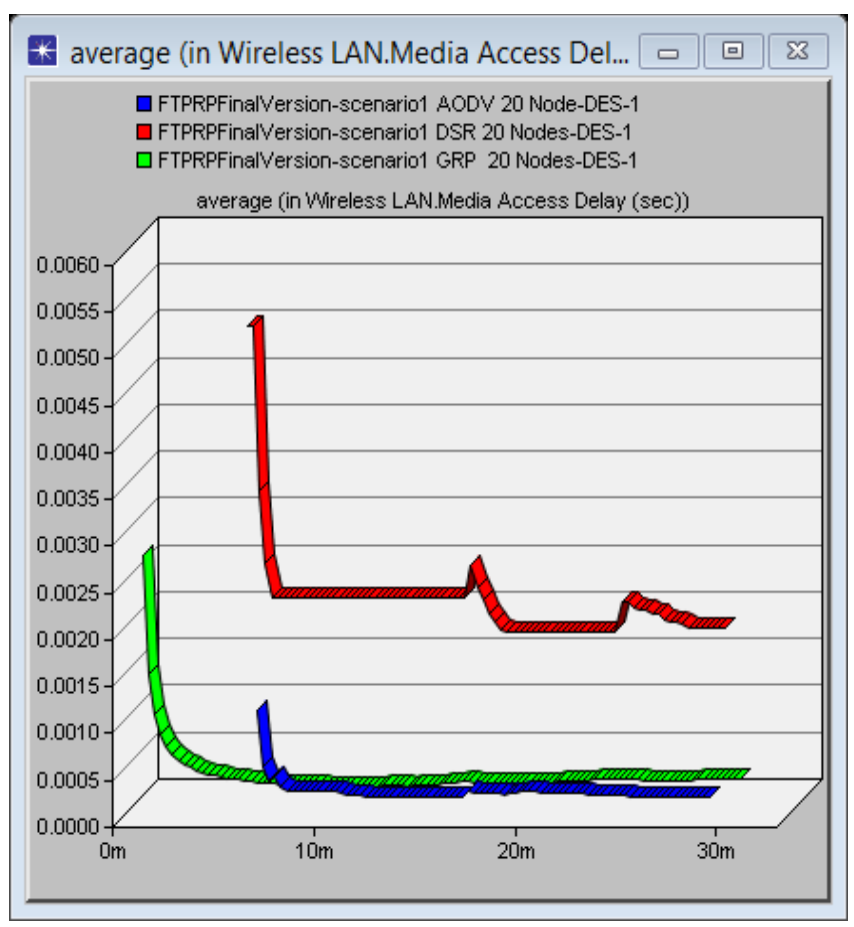

Fig. 7. Media Access Delay for 20 Nodes

In second scenario with the increase mobile nodes from 20 to 40 nodes the Media Access Delay for GRP protocol is decreased gradually and it was low for GRP that is 0.000364 sec. The Media Access Delay for AODV is $0.000857 \mathrm{sec}$ and $0.00503 \mathrm{sec}$ for DSR as shown in Fig. 8 .

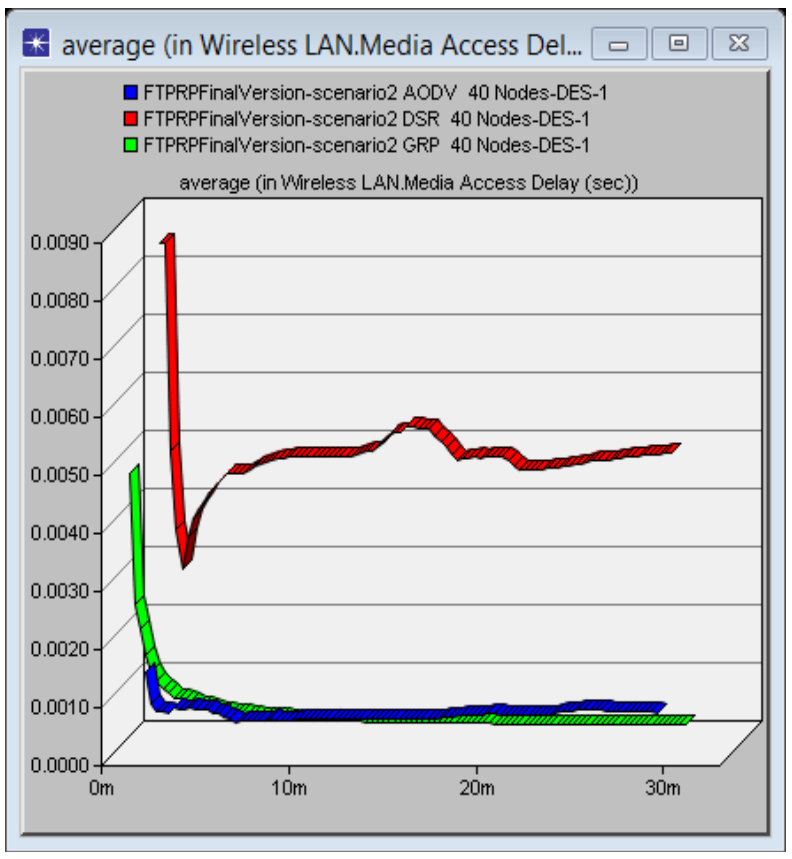

Fig. 8. Media Access Delay for 40 Nodes
In third scenario, when the number of mobile nodes increased to 80, the Media Access Delay for GRP has the lowest as compared to AODV and DSR as shown in Fig. 9. In this scenario the average peak value for GRP is $0.000542 \mathrm{sec}$, $0.00247 \mathrm{sec}$ for AODV and $0.00935 \mathrm{sec}$ for DSR as illustrate in Table 2. The overall results in third scenario for Media Access Delay showed as it is clear from the Table 2 and Fig. 9 presented that the GRP protocol has ability to provide the low Media Access Delay as compared to AODV and DSR. In addition, Media Access Delay of DSR incurs the highest delay due to DSR to find the route it takes more time and every intermediate node tries to extract and record information before forwarding a reply. Furthermore, AODV gives the lower Media Access Delay as compared to DSR due to AODV uses route discovery process to cope with routes on demand basis. It uses routing tables for maintain routing information. It does not need to maintain routes to nodes that are not communicating. As per analysis, we can conclude that GRP protocol is best performer as compared to all other protocols and DSR protocol is the worst performer.

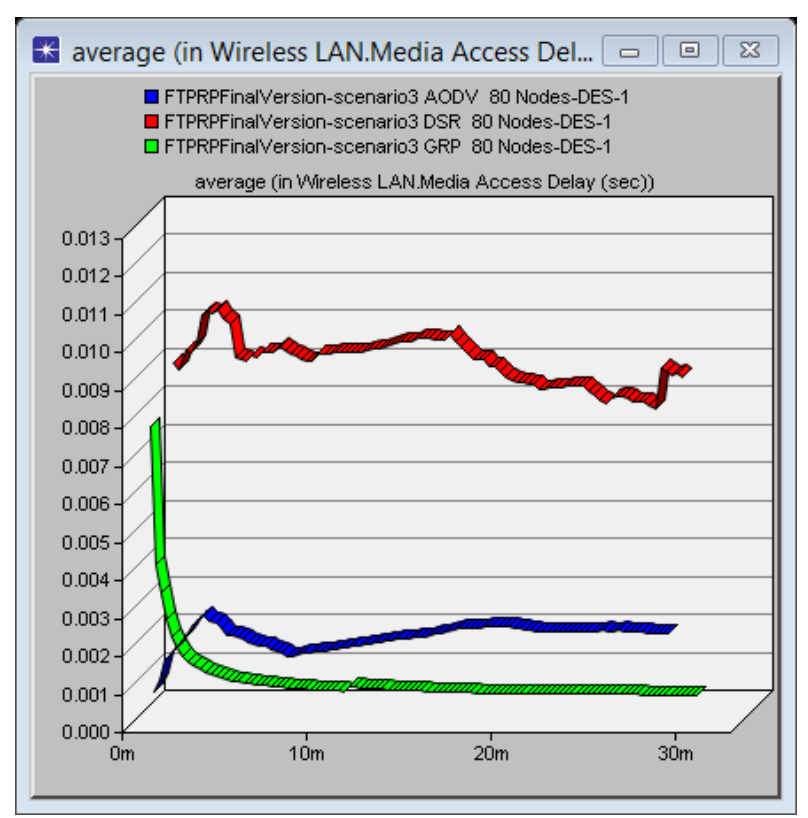

Fig. 9. Media Access Delay for 80 Nodes

\section{Network Load}

To evaluate the network load of AODV, DSR and GRP we have generated three scenarios. In first scenario when the number of mobile nodes is 20, DSR performs better than AODV and GRP protocols. The average peak value of Network Load for DSR 336.101 bits/sec whereas in the GRP routing protocol, the average peak value of Network Load is $3300.384 \mathrm{bits} / \mathrm{sec}, 918.814 \mathrm{bits} / \mathrm{sec}$ for AODV. In this scenario from our experimental analysis we concluded that DSR produces low average Network Load as compared to AODV and GRP as shown in Fig. 10. 


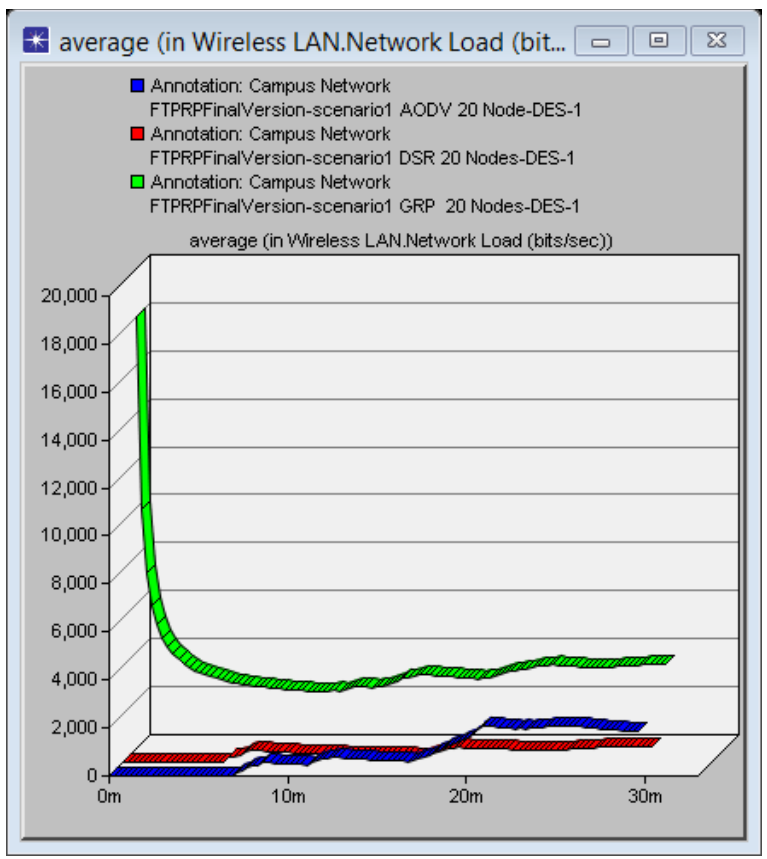

Fig. 10. Network Load for 20 Nodes

In second scenario, when the number of mobile nodes increased into 40. The Network Load of these three routing protocols shows many differences by varying number of nodes. Fig. 11 depicts the performance on the basis of Network Load. In this figure X-axis denotes time in minutes and $\mathrm{Y}$-axis denotes bits. It shows that the average peak value of Network Load is 5757.248 bits/sec for AODV, 3269.774 bits/sec for DSR and 8319.418 bits/sec for GRP protocol. From graph and table results it is observed that DSR has less average Network Load as compared to the AODV and GRP protocols.

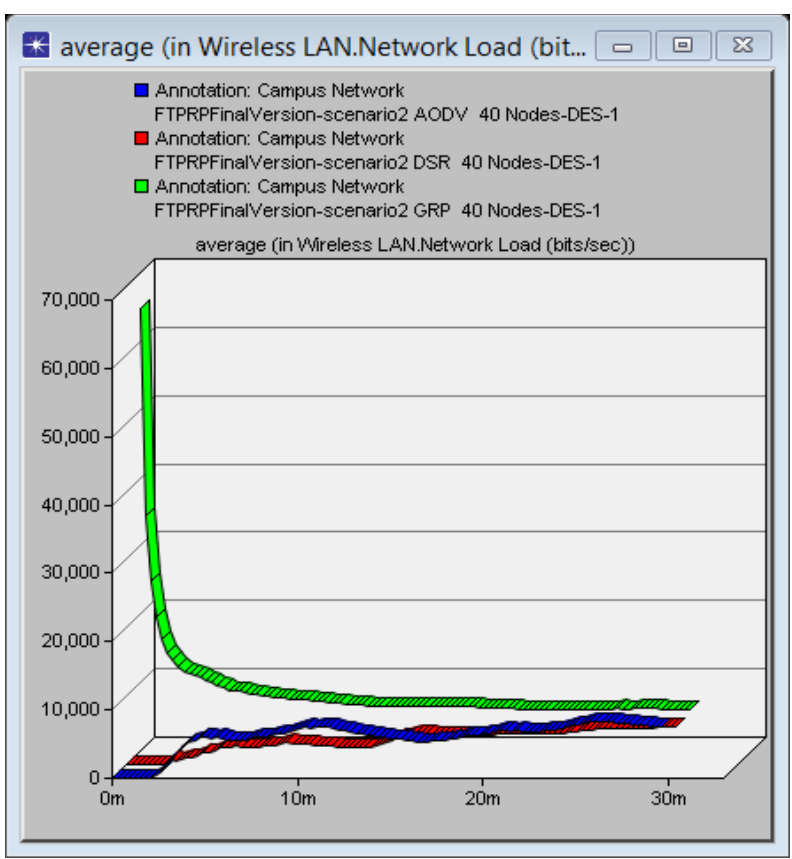

Fig. 11. Network Load for 40 Nodes
In third scenario, the simulation results for the 80 nodes on AODV, DSR and GRP protocols over FTP traffic shows that the Network Load for DSR routing protocol is lower than that of AODV and GRP protocol as illustrate in Fig. 12 and the average peak value is $17224.522 \mathrm{bits} / \mathrm{sec}$ for DSR. In addition, from large network of 80 mobile nodes it is concluded that GRP has the lower Network Load as compared to the AODV protocol and the average peak value for AODV is 22600.635 bits/sec, 20467.897 bits/sec for GRP protocol.

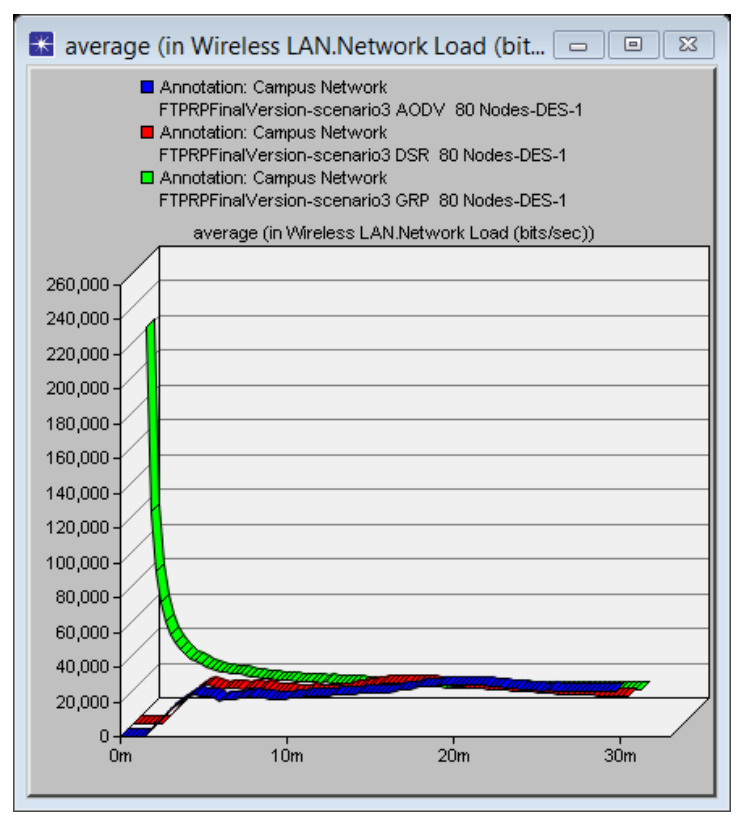

Fig. 12. Network load for 80 Nodes

In all the scenarios, with the increased mobile node numbers, the Network Load is increased. According to the results, it was able to answers the question "Which routing protocol is performing lower Network Load?" As seen from the above graphs and below table that DSR protocol has low average Network Load as compared to the AODV and GRP because it's on demand routing characteristics so there is no needed to update the routing table. In addition, in small and medium network size AODV has the lower Network Load as compared to GRP protocol.

\section{Retransmission Attempt}

Retransmission Attempt of AODV, DSR and GRP protocols in three scenarios are presented in Fig. 13, Fig. 14 and Fig. 15.

In first scenario is developed using 20 mobile nodes with AODV, DSR and GRP routing protocols to analyze their performance for Retransmission Packet Attempt over FTP traffic. The designed model is simulated for 30 minutes and then results are collected after finishing the simulation setup. In Fig. 13 we can see that the Retransmission Attempt results for 20 mobile nodes. According to the results AODV and DSR showing quite high Retransmission Packet Attempt compared to GRP protocols. In this scenario the average peak value for AODV is $0.0321 \mathrm{packet} / \mathrm{sec}, 0.0374 \mathrm{packet} / \mathrm{sec}$ for DSR and $0.0117 \mathrm{packet} / \mathrm{sec}$ for GRP protocol. 


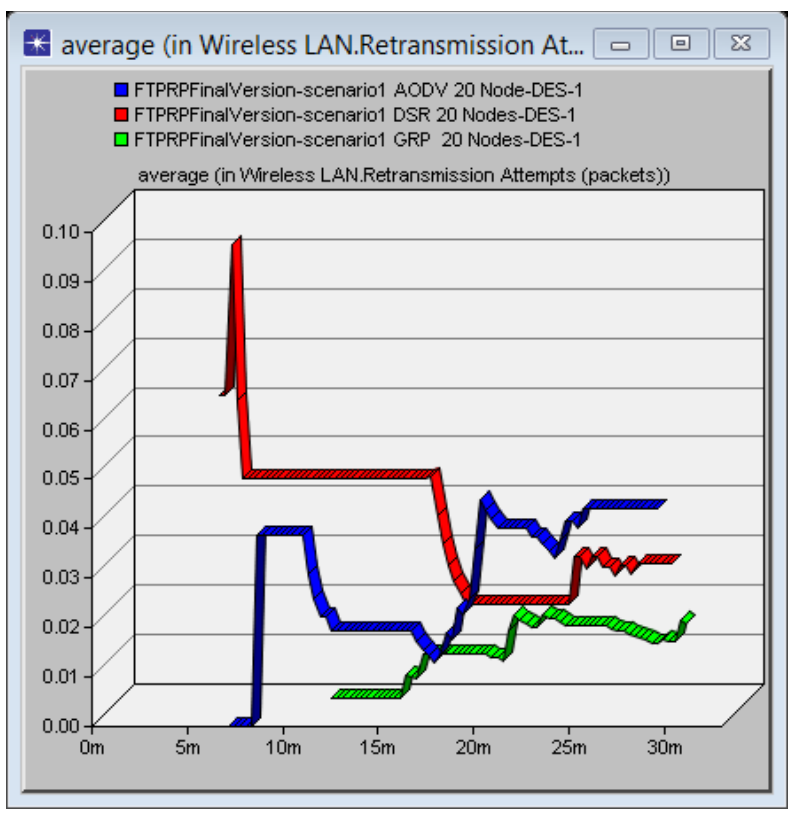

Fig. 13. Retransmission Packet Attempt for 20 Nodes

In second scenario, the simulation results for 40 mobile nodes in case of Retransmission Attempt shown in Fig. 14. We can see that DSR protocol shown high Retransmission Packet Attempt than AODV and GRP and sharply increased the Retransmission packet Attempt with increase time.

In this scenario, the result of Retransmission Attempt of GRP for 40 nodes to transfer FTP application shows has less Retransmission packet. The average peak value for GRP is 0.0395packet/sec, 0.0751 packet/sec for AODV and $0.276 \mathrm{packet} / \mathrm{sec}$ for DSR protocol.

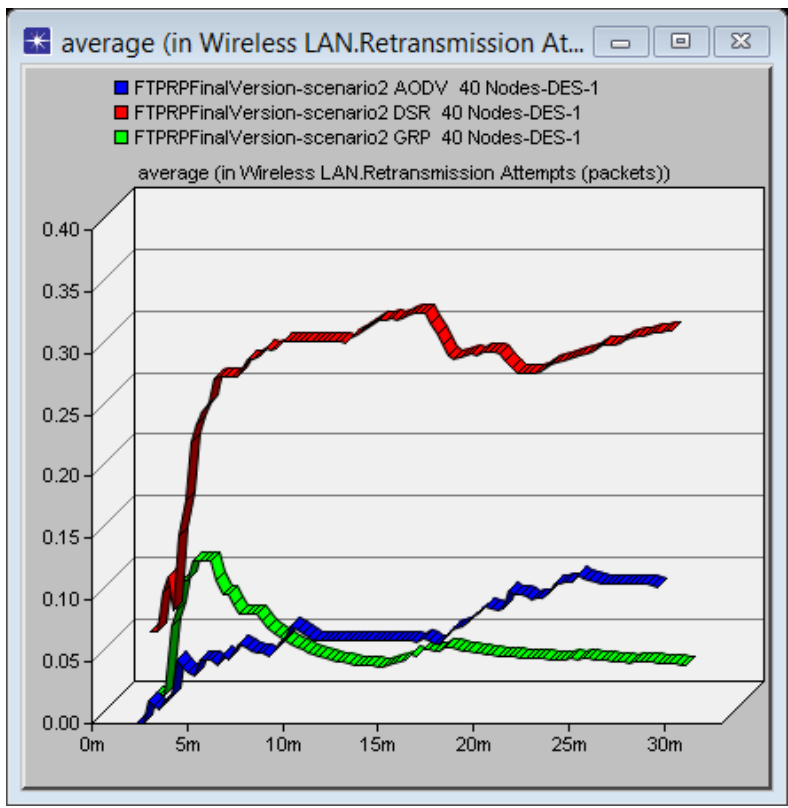

Fig. 14. Retransmission Packet Attempt for 40 Nodes
In third scenario, simulation environment is developed using 80 mobile nodes as the same privously scenario node moving with constant speed $20 \mathrm{~m} / \mathrm{s}$ and AODV, DSR and GRP protocols performce is analyzed. Our simulation results show that GRP protocol show less Retransmission Attempt under medium FTP traffic load than compared to the AODV and DSR protocols. In case of Retransmmission Attempt for GRP is 0.05044packet/sec, 0.3106packet/sec for AODV whereas for DSR it is $0.3531 \mathrm{packet} / \mathrm{sec}$.

On comparing the Fig. 15 we can observe that Retransmission Attempt for AODV protocol gradually is increased and then after 5 minutes the Retransmission Attempt is decreased. Finally for simulation results conclude GRP protocol shows lower Retransmission Attempt on increasing the nodes due to the source node of GRP protocol gathers all network information with the lowest number of control overheads. The source node can find the best route depending on the gathered position information and transmit the data continuously even if the current route is disconnected. This help to achieve a fast transmission with lowest control messages as overhead. Moreover, AODV protocol has ability to provide lower Retransmission Attempts in large network compared to DSR protocol.

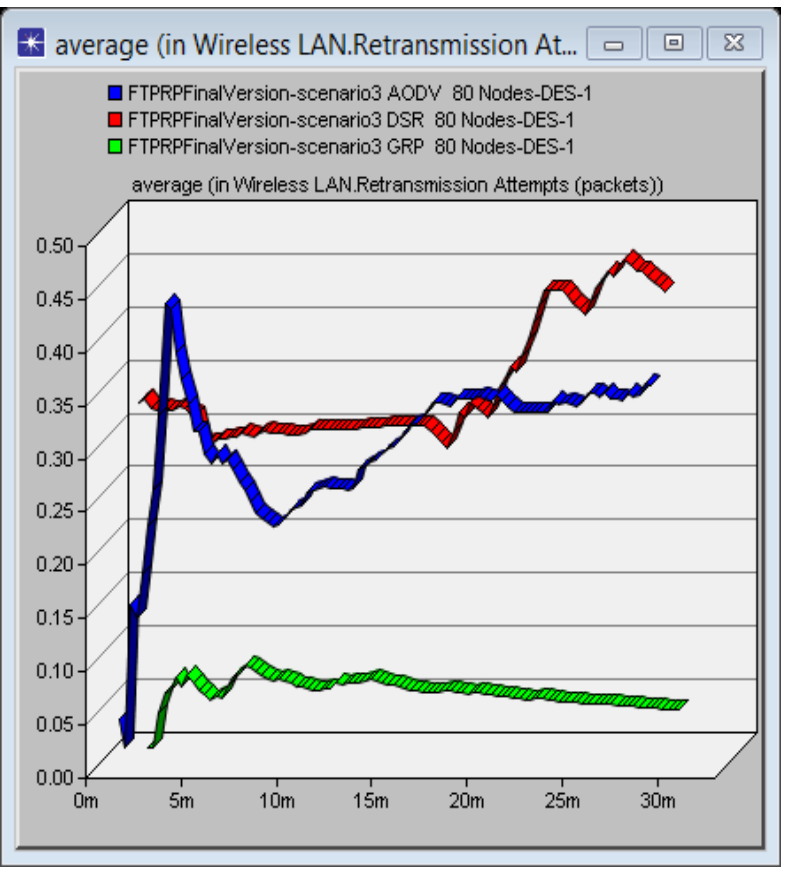

Fig. 15. Retransmission Packet Attempt for 80 Nodes

\section{E. Throughput}

Fig. 16 compares the average throughput of AODV, DSR and GRP protocols for 20 mobile nodes. As illustrate in figure, throughput of GRP performs best in delivering 49153.4313 bits/sec a data as compared with the other two protocols and AODV performed well achieving throughput of 8142.914 bits/sec than DSR 456.2699 bits/sec. 


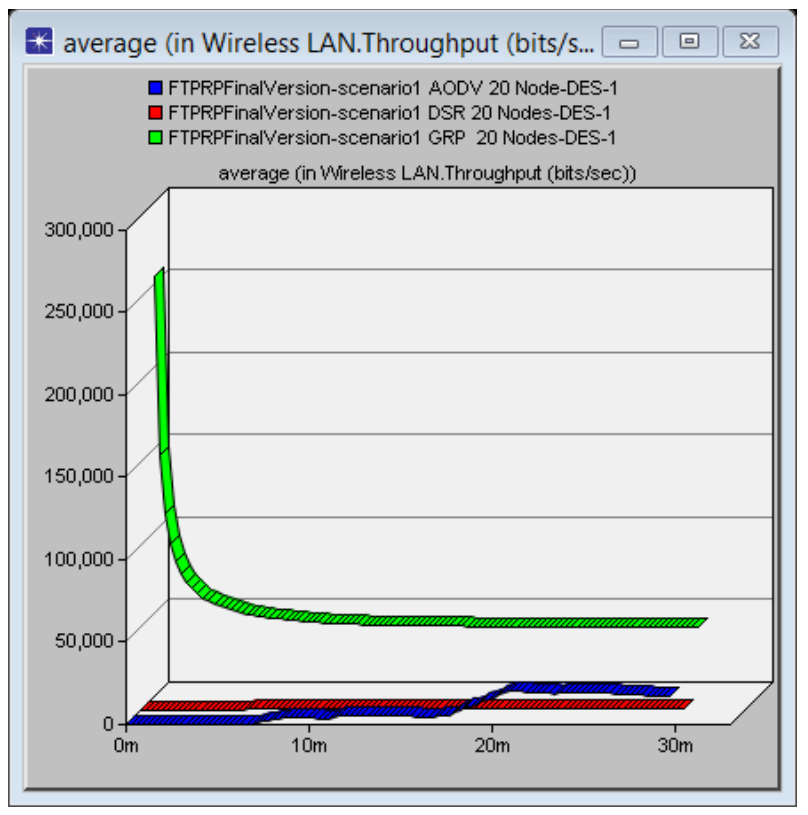

Fig. 16. Throughput for 20 Nodes

In second scenario under the 40 mobile nodes with regard to the throughput metric, the GRP clearly has the highest throughput as seen in Fig. 17. In this scenario, DSR has the lowest while AODV has a medium throughput. GRP throughput rate reaches up to the peak of $201979.159 \mathrm{bits} / \mathrm{sec}$ with passage of time while AODV gives the throughput rate which above than $172811.127 \mathrm{bits} / \mathrm{sec}$ with a decrease in throughput in the middle and DSR gives the throughput rate $20189.736 \mathrm{bits} / \mathrm{sec}$. in this scenario, according to the obtained results for the 40 mobile nodes shows that the throughput for GRP routing protocol is higher than that of AODV and DSR routing protocols.

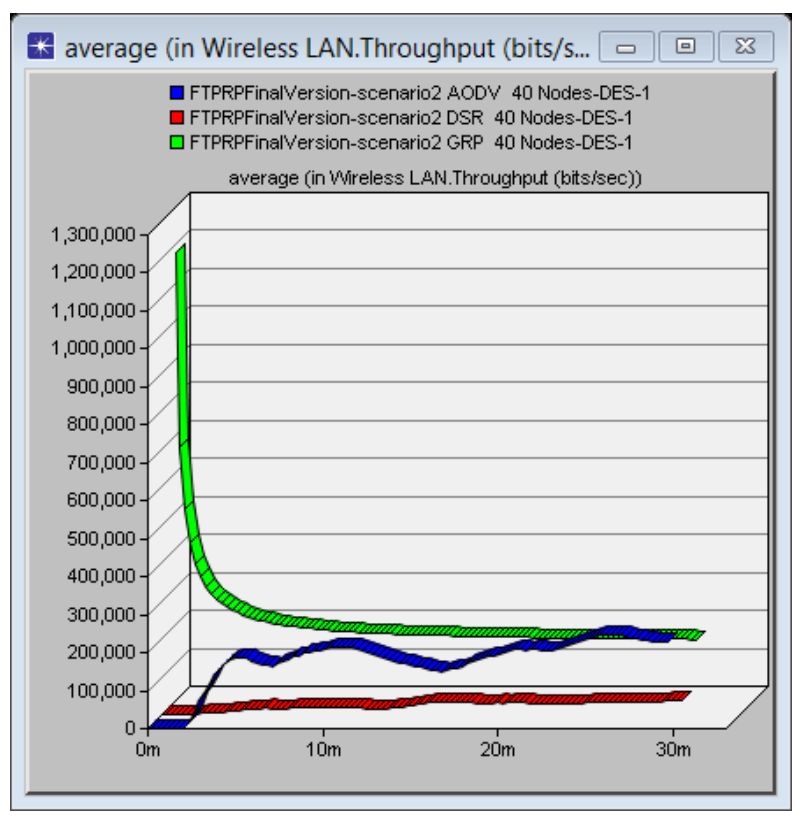

Fig. 17. Throughput for 40 Nodes

In third scenario, we increased the number of mobile nodes from 40 to 80 nodes to check the behavior of the routing protocols. From large network of 80 mobile nodes AODV throughput is $1177038.351 \mathrm{bits} / \mathrm{sec}$ and performed particularly better than DSR and GRP as shown in Fig. 18. As the previously scenarios we are keeping the mobility and packet length constant. The peak value of GRP throughput is $840348.805 \mathrm{bits} / \mathrm{sec}$ and the peak value of DSR is 251467.513 bits/sec.

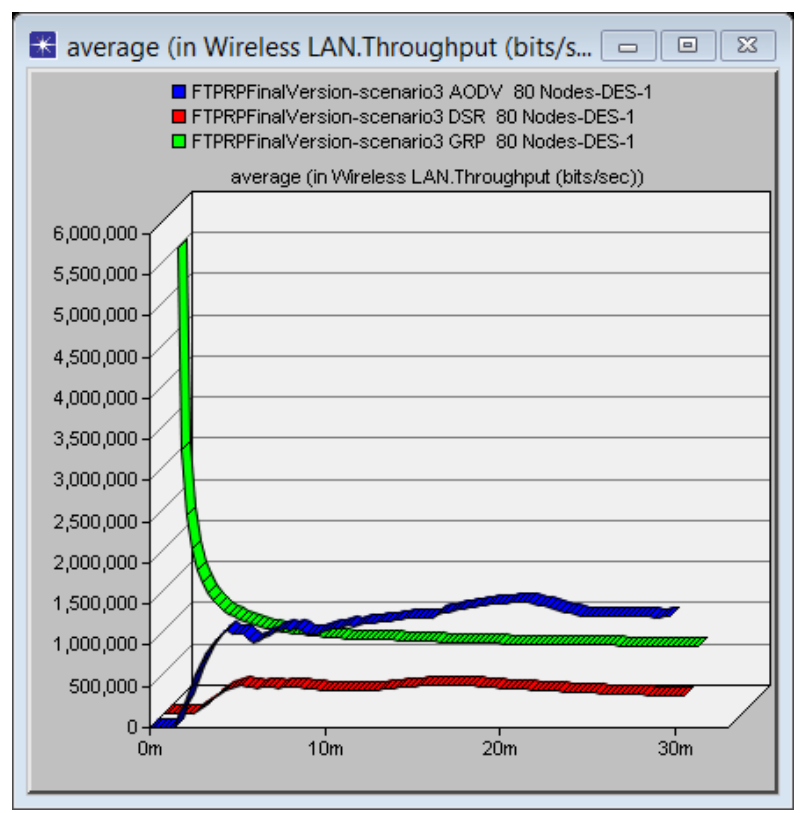

Fig. 18. Throughput for 80 Nodes

Refer to Fig. 16, 17 and 18. From the figures we can observe that the throughput rate of GRP in small and medium networks higher than the throughput rate of AODV and DSR because the GRP routing protocol gathering information rapidly at a source node without spending large amount of overheads but in case of large networks the difference is prominent and AODV by far performs better than GRP and DSR due to AODV protocol follows a routing mechanism known as hop by hop and removes the overhead of the source routing within the network related to above. The availability of multiple route information in the AODV assists in producing the higher amount of throughput in the network. Whereas DSR protocol follows a source routing mechanism and the byte overhead in each packet extremely affects the total byte overhead when the network traffic increases. Resulting, the DSR protocol tends to achieve lower amount of data packets in more stressful network.

TABLE II. Average VALUe RESUlts of THREe SCENARIOS FOR AODV, DSR AND GRP PROTOCOLS

\begin{tabular}{|l|l|l|l|l|}
\hline Protocols & Metrics & 20 Nodes & 40 Nodes & 80 Nodes \\
\hline & $\begin{array}{l}\text { End-to-End } \\
\text { Delay(sec) }\end{array}$ & 0.0003948 & 0.000932 & 0.00185 \\
\cline { 2 - 5 } & $\begin{array}{l}\text { Media Access } \\
\text { Delay(sec) }\end{array}$ & 0.000362 & 0.000857 & 0.00247 \\
\cline { 2 - 5 } AODV & $\begin{array}{l}\text { Network } \\
\text { Load(bit/sec) }\end{array}$ & 918.841 & 5757.248 & 22600.635 \\
\cline { 2 - 5 } & $\begin{array}{l}\text { Retransmission } \\
\text { Attempt(Packet) }\end{array}$ & 0.0321 & 0.0751 & 0.3106 \\
\cline { 2 - 5 } & $\begin{array}{l}\text { Throughput } \\
\text { (bit/sec) }\end{array}$ & 8142.914 & 172811.127 & 1177038.351 \\
\hline
\end{tabular}




\begin{tabular}{||l|l|l|l|l|}
\hline \multirow{5}{*}{ DSR } & $\begin{array}{l}\text { End-to-End } \\
\text { Delay(sec) }\end{array}$ & 0.0020406 & 0.00434 & 0.00648 \\
\cline { 2 - 5 } & $\begin{array}{l}\text { Media Access } \\
\text { Delay(sec) }\end{array}$ & 0.00221 & 0.00503 & 0.00935 \\
\cline { 2 - 5 } & $\begin{array}{l}\text { Network } \\
\text { Load(bit/sec) }\end{array}$ & 336.101 & 3269.774 & 17224.522 \\
\cline { 2 - 5 } & $\begin{array}{l}\text { Retransmission } \\
\text { Attempt(Packet) }\end{array}$ & 0.0374 & 0.276 & 0.3531 \\
\cline { 2 - 5 } & $\begin{array}{l}\text { Throughput(bit/s } \\
\text { ec) }\end{array}$ & 456.2699 & 20189.736 & 251467.513 \\
\hline \multirow{5}{*}{ GRP } & $\begin{array}{l}\text { End-to-End } \\
\text { Delay(sec) }\end{array}$ & 0.0003903 & 0.000534 & 0.000719 \\
\cline { 2 - 5 } & $\begin{array}{l}\text { Media Access } \\
\text { Delay(sec) }\end{array}$ & 0.000188 & 0.000364 & 0.000542 \\
\cline { 2 - 5 } & $\begin{array}{l}\text { Network } \\
\text { Load(bit/sec) }\end{array}$ & 33.00384 & 8319.418 & 20467.897 \\
\cline { 2 - 5 } & $\begin{array}{l}\text { Retransmission } \\
\text { Attempt(Packet) }\end{array}$ & 0.0117 & 0.0395 & 0.05044 \\
\cline { 2 - 5 } & $\begin{array}{l}\text { Throughput(bit/s } \\
\text { ec) }\end{array}$ & 49153.4313 & 201979.159 & 840348.805 \\
\hline
\end{tabular}

[3] A. Ako, et al., "The Impact of Reactive Routing Protocols for Transferring Multimedia Data over MANET," Journal of Zankoy Sulaimani-Part A, vol. 4, no. 16, 2014.

[4] A. Al Maashri, et al., "Performance Analysis of MANET Routing Protocols In The Presence Of Self-Similar Traffic,". Local Computer Networks, Proceedings 2006 31st IEEE Conference on (2006): pp. 801 807.

[5] R. kumar, "A Fault Tolerant Congestion Aware Routing Protocol For Mobile Ad-hoc Networks," Journal of Computer Science vol. 8, no. 5, pp. 673-680, 2012.

[6] K. Sapna, et al., "Comparison of effectiveness of AODV, DSDV and DSR Routing Protocols in Mobile Ad-hoc Networks," International Journal of Information Technology and Knowledge Management, vol. 2, no .2, pp. 499$502,2009$.

[7] G. IJatin, et al., "A Review of Performance Evaluation of the Routing Protocols in Manets," International Journal of Advanced Research in Computer Science \& Technology (IJARCST), vol. 2. No. 2, pp. 46-48, 2014.

\section{CONCLUSION \& FUTURE WORK}

In this study analyzed the performance of AODV, DSR and GRP routing protocols by varying number of mobile nodes from 20 (low density), 40 (medium density) to 80 (high density) to transfer FTP application over MANET network in terms of End-to-End Delay, Media Access Delay, Network Load, Retransmission Attempt and Throughput. In this paper to generate node mobility, we used Random Way Point Mobility Model with the speed of 20 meters/second in an area of $1200 \times 1200 \mathrm{~m}$. In this experiment we found that the performance varies widely across different network size and results from one scenario cannot be applied to those from the other scenario. From the simulation results we can conclude that average End-to-End Delay, Media Access Delay and Retransmission Attempt of GRP routing protocol in all scenarios is much better than AODV and DSR protocols However, GRP protocol provides the best Throughput in small and medium network size and GRP protocol in terms of Network Load shows high average Network Load as compared to DSR routing protocol. As far as Network Load of GRP perform better than the AODV from large network. In addition, the study demonstrate that AODV has less End-toEnd Delay, Media Access Delay, Retransmission Attempt and high Throughput for FTP application compared to DSR protocol and we found that average Network Load of DSR in all scenarios is much lower than GRP and AODV.

In the future work, we will conduct with a new technique to improve security issues in AODV and DSR routing protocols.

\section{ACKNOWLEDGMENT}

I would like to thank University of Sulaimani- Kurdistan Region- Iraq for their helps and supports in the implementation in my research.

\section{REFERENCES}

[1] C. Imrich, et al., "Mobile Ad-hoc Networking: Imperatives and Challenges". Ad-hoc Networks, vol. 1, no. 1, pp. 13-64, 2003.

[2] N. Parma, et al., "Mobility Based Performance Analysis DYMO, STAR And DSR Adhoc Routing Protocols," International Journal of Comp. Tech. Appl., vol. 2, mo. (6), pp. 1755-1760, 2011.

[8] N. Valery, et al., "Scalability of Routing Methods in Ad-hoc Networks," Elsevier, vol. 6, no. 2, pp. 193-209, 2005.

[9] C. Manish, "Simulation and Study of AODV Routing Protocol under CBR and TCP Traffic Source," IJET vol. 4, no. 2, pp. 84-88, 2014

[10] M. Debra, et al., "Performance Evaluation on Extended Routing Protocol of AODV in MANET," IJASUC, vol. 4, no. 4, pp. 27-37, . 2013.

[11] M. Mohammad, et al., "Multipath Routing Protocols in Wireless Sensor Networks: A Survey and Analysis," International Journal of Future Generation Communication and Networking, vol. 6, no. 6, pp. 181-192, 2013.

[12] Z. Yan,et al., "Performance Evaluation of Routing Protocols on the Reference Region Group Mobility Model for MANET," International Journal of Wireless Sensor Network, vol. 3, no. 3, pp. 92-105, 2011.

[13] H. Xi et al., "Stability-Based RREQ Forwarding Game For Stability-Oriented Route Discovery in Manets," Wireless Personal Communication, vol. 68, no. 4, pp. 1689-1705, 2012.

[14] K. Venetis et al., "A New RREQ Message Forwarding Technique Based On Bayesian Probability Theory," EURASIP J Wirel Commun Netw, vol. 20, no. 12, pp. 318-325, 2012.

[15] N. Humaira, et al., "Energy Efficient Routing Protocols For Mobile Ad-hoc Networks," International Journal of Computer Applications, vol. 1, no. 4, pp. 121-132, 2011.

[16] S. Samadi, et al., "An Adaptive Multipath Ant Routing Algorithm for Mobile Ad-hoc Networks," IJCEE, vol. 7, no. 3, pp. 175-180, 2012.

[17] M. Reza, et al., "Fundamental Lifetime Mechanisms in Routing Protocols for Wireless Sensor Networks: A Survey and Open Issues'. Sensors, pp. 13508-13544, 2012.

[18] A. Rabia, et al., "Bandwidth Estimation in Mobile Ad-Hoc Network (MANET)," International Journal of Computer Science (IJCSI), vol. 8, no. 5, pp. 331-337, 2011.

[19] S. Alka, "Power Efficient Scheme for Performance Optimization in Adhoc Networks," International Journal of Computer Applications, vol. 14, no .6, pp. 38-42, 2011.

[20] B. Stefano et al., "Mobile Ad-hoc Networking," Piscataway, NJ: IEEE Press, 2004.

[21] G. Parul, et al., "Energy-Efficiency Based Analysis of Routing Protocols in Mobile Ad-Hoc Networks (Manets)," International Journal of Computer Applications, vol. 96, no. 15, pp 15-23, 2014.

[22] M. Mahesh, et al., "Ad-hoc on-demand multipath distance vector routing." Wireless Communications and Mobile Computing, vol. 6, no. 7, pp. 969-988, 2006.

[23] N. Singla, et al., "A Review of Performance Evaluation of the Routing Protocols in MANETs," International Journal of Innovative Research in Computer and Communication Engineering, vol. 2, Issue. 11, pp.63606364, 2014.

[24] X. Ya, et al., "Geography-informed energy conservation for ad-hoc routing" Proceedings of the 7th annual international conference on Mobile computing and networking. ACM, 2001. 
[25] F. Bai, et al., "IMPORTANT: A framework to systematically analyze the Impact of Mobility on Performance of Routing protocols for Ad-hoc Networks," INFOCOM 2003. Twenty-Second Annual Joint Conferences of the IEEE Computer and Communications. IEEE Societies. vol. 2. IEEE, 2003.

[26] I. Stojmenovic, "Position-based routing in ad-hoc networks," IEEE Communications Magazine, vol. 40, Issue 7, pp.128-134, 2012.

[27] R. Bassel et al., "Multipath Grid-Based Enabled Geographic Routing For Wireless Sensor Networks," Wireless Sensor Network, vol. 6, no. 12, pp. 265280, 2014.

[28] K. Shwaita, et al., "Energy Efficient Geographical Routing Protocol with Location Aware Routing in MANET," International Journal of Advanced Research in Computer Engineering \& Technology (IJARCET), vol. 1, no. 5 pp. $172-182,2014$

[29] Y. Yan, et al., "Geographical and energy aware routing: A recursive data dissemination protocol for wireless sensor networks," Technical report ucla/csdtr-01-0023, UCLA Computer Science Department, 2001.

[30] A. Boussad, et al., "A Hybrid Multi agent Routing Approach for Wireless Adhoc Networks," Wireless Networks vol. 18, no. 7, pp. 837-845, 2012.

[31] F. Maan, et al., "MANET Routing Protocols vs. Mobility Models: A Performance Evaluation,” Proc. of IEEE-ICUFN, 2011.
[32] M. Narendra et al., "Performance Evaluation of AODV and DSR Routing Protocols for Vehicular Ad-hoc Network (VANETs)," International Journal of Emerging Technology and Advanced Engineering, vol. 4, Issue 6, pp. 522-530, 2014.

[33] G. Vikas, et al., "Performance Investigation of Routing Protocols for Database and Voice Data in MANETS," International Journal of Emerging Trends \& Technology in Computer Science, ISSN 2278-6856, vol. 2, Issue 4, pp. 326332, 2013.

[34] A. Akshai,, et al., "Performance Analysis of AODV, DSDV and DSR in MANET," International Journal of Distributed and Parallel System, vol. 2, no. 6, pp. 167-177, 2011.

[35] A. Ainiwan et al., "A Novel Multicarrier CDMA Scheme With Interference Free Performance In Very Large Delay Spread," ITE Transactions on Media Technology and Applications, vol. 2, no. 4, pp. 362-369, 2014.

[36] D. Holmer, et al., "The Medium Time Metric: High Throughput Route Selection In Multi-Rate Ad-hoc Wireless Networks," Mobile Networks and Applications, vol. 11, no. 2, pp. 253-266, 2006.

[37] B. Devendra, et al., "Performance Evaluation Of MAC Protocol For IEEE 802. 11, 802. 11Ext. WLAN And IEEE 802. 15. 4 WPAN Using NS-2," International Journal of Computer Applications, vol. 119, no. 16, pp. 25- 30, 2015 . 